\title{
O QUE É EFETIVIDADE?*
}

WHAT IS EFFECTIVE

Wilfredo Eduardo Martinez Galindo**

\begin{abstract}
"Cuando voy al trabajo pienso en ti compañera de mis dias y del porvenir (...) laborando el comienzo de una historia sin saber el fin (...) cuando llego a la casa esta ahi y amarramos los sueños" (Victor Jara).
\end{abstract}

Resumo:

O presente trabalho analisa a Efetividade processual no contexto socioeconômico e jurídico, parte do pressuposto que é a vontade política do Estado, em resposta as demandas dos atores sociais, que determina a escolha e a ênfase dos princípios que norteiam a positivação das normas processuais.

O estudo do conceito de Efetividade e dos princípios na doutrina processualista são analisados para a confirmação da hipótese pesquisada.

Palavras chaves: Efetividade. Conceito. Princípio Processual. Instrumentalidade no Sentido Positivo. Reformas do CPC.

\section{Resumen:}

El presente trabajo analiza la Efectividad procesal en el contexto socioeconómico y jurídico, parte del supuesto que es voluntad política del Estado, en respuesta a las demandas de los actores sociales y que determina la elección y el énfasis de los principios que orientan el positivismo de las normas procesales.

El estudio del concepto de Efectividad y de los principios de la doctrina procesal es analizado para la confirmación de la hipótesis investigada.

Palabras claves: Efectividad. Concepto. Principio Procesal. Instrumentar en el sentido positivo. Reformas del CPC.

\section{Introdução}

Uma das maiores ausências que se nota nas obras de Direito, com raríssimas exceções, é a falta de perspectiva histórica e a omissão das forças sociais e econômicas que impulsionam e determinam a positivação das leis, talvez os jusfilósofos analisem os fenômenos jurídicos com suposta isenção e se preocupem apenas com a sua mera aplicação técnica.

\footnotetext{
- Artigo Científico apresentado ao Programa de Educação Continuada e Especialização em Direito Processual Civil - GVLaw, como exigência parcial para aprovação na disciplina Planejamento da Pesquisa, no ano letivo de 2009, sob a orientação do Professor Sidnei Amendoeira Júnior. Dedico este trabalho a minha mulher Maria Lúcia de Oliveira Martinez.

• $\quad$ Bacharel pela Faculdade de Direito da Universidade de São Paulo e advogado.
} 
Os filósofos se limitaram a interpretar o mundo de diferentes maneiras; o que importa é transformá-lo. (MARX e ENGELS. 1982, p. 14).

Este artigo parte do pressuposto que os fatores econômicos e sociais são determinantes para as mudanças de paradigma do mundo jurídico e a Efetividade é antes de tudo uma vontade política do legislador que responde as demandas dos atores sociais em determinado momento histórico.

Sabe-se que a missão do direito processual é tornar possível a realização do direito material, criando os instrumentos indispensáveis à realização desse objetivo. A opção por um ou outro instrumento será uma tarefa do político e não do processualista, enquanto produtor de normas processuais. (SILVA, 2006, p. 34), (grifos nossos).

É necessário recordar que o atual Código de Processo Civil foi instituído pela Lei n. 5.869, de 11 de janeiro de 1973, sancionada pelo General Emílio Garrastazu Médici, ou seja, em plena ditadura militar.

O referido CPC, como é notório, foi redigido por Alfredo Buzaid, Ministro da Justiça "em consonância com o progresso científico dos tempos atuais" (Exposição de Motivos do Código de Processo Civil), em outras palavras, em consonância com a necessidade de dar segurança jurídica para as transnacionais e o capital estrangeiro e nacional, cujo objetivo era dar sustento ao "milagre brasileiro"

\begin{abstract}
A política econômica dos governos militares aprofundou o modelo de industrialização acelerada dos anos JK. O setor de bens de consumo duráveis se tornava definitivamente o mais dinâmico da economia. Os subsídios estatais e o baixo custo da mão-de-obra ofereciam excelentes condições para a instalação de novas empresas multinacionais no país.

(...)

Os anos do 'milagre' cristalizaram um modelo econômico baseado em uma tríplice aliança, da qual faziam parte o capital estatal, os conglomerados transnacionais e o grande capital nacional. O tripé conjugava os interesses dos grandes oligopólios que lotearam o mercado brasileiro(...) (MAGNOLI, 1992, p. 62 e 63).
\end{abstract}

É óbvio que transcorridos trinta e sete anos da vigência do CPC a realidade socioeconômica mudou de forma radical, posto que já não vivemos num mundo bipolar, de mercado fechado e regime autoritário, encontramo-nos em um mundo globalizado, com abertura de mercado e regime democrático, cujo corolário jurídico é a Constituição Federal de 1988, denominada de "Constituição Cidadã" assim, com a mudança da estrutura também faz-se necessário a mudança da superestrutura. 
Os novos fatos obrigaram à revisão de toda a história anterior, e então viu-se que, com exceção do Estado primitivo, toda a história anterior era a história das lutas de classes, e que essas classes sociais em luta entre si eram em todas as épocas fruto das relações de produção e de troca, isto é, das relações econômicas da sua época; que a estrutura econômica da sociedade em cada época da história constitui, portanto, a base real cujas propriedades explicam, em última análise, toda a superestrutura integrada pelas instituições jurídicas e políticas, assim como pela ideologia religiosa, filosófica, etc., de cada período histórico (...) (ENGELS, São Paulo, 1983, p. 52), (grifos nossos).

O atual CPC que entrou em vigor em 1973 já foi alterado por 64 normas até hoje. Para o ministro Fux, as recentes reformas foram 'magnificas' no sentido de dar maior efetividade a prestação judicial, ainda mais diante do volume de processo que o Judiciário brasileiro tem enfrentado. (Redução de recursos não violará ampla defesa, diz Fux - Consultor Jurídico. 26.10.2009).

Por outro lado, o tradicional modelo de investigação científica do Direito desprovido da realidade socioeconômica não é suficiente para os fins do presente artigo.

Em nosso socorro e com sua peculiar profundidade teórica o jurista José

Eduardo Faria assevera:

À medida que o tradicional modelo de 'direito positivo' entra em crise de identidade, funcionalidade e eficácia, acarretando com isso uma crescente erosão do rigor analítico e do potencial explicativo dos esquemas teóricos desenvolvidos com base no primado do monismo jurídico, outro modelo vai surgindo. Ainda que suas linhas arquitetônicas não estejam consolidadas e muitos de seus institutos e categorias se encontrem em fase de incubação, o novo modelo já conta com alguns contornos razoavelmente precisos. Por exemplo, ele se destaca por suas feições pluralistas, sob a forma de redes de legalidade justapostas ou paralelas, resultantes não apenas de decisões emanadas de instituições governamentais, como o Legislativo e o Executivo, mas igualmente, de negociações e deliberações nos diferentes sistemas e subsistemas que compõem a economia e a sociedade. Trata-se de um direito cuja produção normativa cada vez mais se dá em instâncias não-legislativas, motivo pelo qual seu conteúdo normativo não é determinado apenas e tão-somente pelo Estado, porém pactuado por diferentes atores - empresas, fundações, associações comunitárias, entidades de classe, órgãos de representação corporativa e organizações não-governamentais (ONGs). Por isso, é um tipo de direito que tende a se fundamentar numa legitimidade de caráter eminentemente procedimental - portanto, uma 
legitimidade vinculada ao seu modo de elaboração. (FARIA, 2008, p. 07), (grifos nossos).

Posto isto, passamos a analisar o conceito de Efetividade e sua aplicação no mundo jurídico, porém sem perder a perspectiva ideológica do objeto analisado.

2. O conceito de efetividade

A palavra Efetividade no senso comum é derivada de efetivo, que significa: "positivo, estável, seguro (...) lefféctivo XVII | Do lat. Effectivus -a-um $\|(\ldots)$ ". (CUNHA, 1982).

"[Do lat. Effectivu.] Adj. 1. Que se manifesta por um efeito real; positivo (...) S. m. 4. O que existe realmente. (...)" (FERREIRA, 2004).

Assim, efetividade é:

"[D efetivo + (i)dade.] S.f. 1. Qualidade de efetivo. 2. Atividade real; resultado verdadeiro (...) 3. Realidade, existência." (FERREIRA, 2004).

Assim, temos que Efetividade é sinônimo de realidade, existência, certeza, objetividade, sendo que na forma substantiva tem o sentido de realizar, efetuar, perfazer. (FERNANDES, 1957).

Na doutrina processualística o conceito de Efetividade não é necessariamente uniforme, se não vejamos.

Posto que polêmico o conceito de efetividade - no dizer de Augusto Tavares Rosa Marcacini, para se saber o que é efetividade, impõe-se, antes, indagar o que cada um espera do processo (...) (Estudo sobre a efetividade do processo civil. Tese de doutorado. USP, 1999, p. cit. 39) (apud LOPES e LOPES, 2008, p. 89).

Segundo o mestre Cândido Rangel Dinamarco a Efetividade processual é:

(...) Falar da instrumentalidade nesse sentido positivo, pois, é alertar para a necessária efetividade do processo, ou seja, para a necessidade de ter-se um sistema processual capaz de servir de eficiente caminho à 'ordem jurídica justa' Para tanto, não só é preciso ter a consciência dos objetivos a atingir, como conhecer e saber superar os óbices econômicos e jurídicos que se antepõem ao livre acesso à justiça (supra, n. 8).

(...)

Tudo que já se fez e se pretende fazer nesse sentido visa. como se compreende, à efetividade do processo como meio de acesso à justiçą. E a concretização desse desiderato é algo 
que depende menos das reformas legislativas (importantes embora), do que da postura mental dos operadores do sistema (juízes, advogados, promotores de justiça). É indispensável a consciência de que o processo não é mero instrumento técnico a serviço da ordem jurídica, mas, acima disso, um poderoso instrumento ético destinado a servir à sociedade $\mathrm{e}$ ao Estado. (CINTRA, GRINOVER e DINAMARCO, 2008, p. 47 e 51$)$.

Tal é o significado substancial das garantias e princípios constitucionais e legais do processo. Falar da efetividade do processo, ou da sua instrumentalidade em sentido positivo, é falar da sua aptidão. mediante a observância racional desses princípios e garantias, a pacificar segundo critérios de justiça. Em diversos itens acima examinaram-se os reflexos que essas posturas ideológicas projetam sobre a técnica processual, ou seja, sobre os seus instintos e a disciplina que recebem, segundo as disposições da lei e a interpretação inteligente do estudioso atualizado. (DINAMARCO, 2008, p. 362) (grifos nossos).

Portanto, Efetividade para Cândido Rangel Dinamarco é a instrumentalidade do processo no sentido positivo, ou seja, a relação que liga o sistema processual à ordem jurídico-material e a sociedade ao Estado.

Neste sentido, parte da doutrina agasalha o conceito de Efetividade como "instrumentalidade em sentido positivo".

A efetividade significa, portanto, a realização do Direito, o desempenho concreto de sua função social. Ela representa a materialização, no mundo dos fatos, dos preceitos legais e simboliza a aproximação, tão íntima quanto possível, entre o dever-ser normativo e o ser da realidade social. (BARROSO, Luís Roberto. Interpretação e aplicação da Constituição. São Paulo: Saraiva, 1996. p. cit. 220).

A efetividade está intimamente relacionada com o resultado concreto da prestação jurisdicional, que, aliás, é dever inarredável do Estado, consoante o disposto no art. $5^{\circ}$, inciso XXXV, da Constituição Federal.

(...) A tutela jurisdicional está ligada diretamente à efetividade do processo, considerado genericamente como instrumento de atuação do direito material. A tutela pretendida pelo titular do direito substancial violado só será entregue, como prestação, quando forem efetivos os meios processuais a fazer atuar o direito em favor da pessoa.

Para garantir a efetividade do processo, a lei criou meios de coerção a serem utilizados para evitar o descumprimento de decisões judiciais. (SOUZA, 2003, p. 47).

Sua noção nuclear, no contexto adotado para o desenvolvimento deste Curso, repousa em verificar que, uma vez obtido o reconhecimento do direito indicado como 
ameaçado ou lesionado, e que, por isto mesmo, justifique a atuação do Estado-juiz (a prestação da 'tutela jurisdicional'), seus resultados devem ser efetivos, isto é, concretos, palpáveis, sensíveis no plano exterior do processo, isto é, 'fora' do processo. (BUENO, 2008, p. 148).

O eminente professor Bedaque aprofunda o estudo da efetividade partindo dos postulados de Dinamarco, se não vejamos:

\section{"10. Efetividade do processo.}

Processo efetivo é aquele que, observado o equilíbrio entre os valores segurança e celeridade, proporciona às partes o resultado desejado pelo direito material. Pretende-se aprimorar o instrumento estatal destinado a fornecer a tutela jurisdicional. Mas constitui perigosa ilusão pensar que simplesmente conferir-lhe celeridade é suficiente para alcançar a tão almejada efetividade. Não se nega a necessidade de reduzir a demora, mas não se pode fazêlo em detrimento do mínimo de segurança, valor também essencial ao processo justo.

Em princípio, não há efetividade sem contraditório e ampla defesa. A celeridade é apenas mais uma das garantias que compõem a idéia de devido processo legal, não a única. A morosidade excessiva não pode servir de desculpa para o sacrifício de valores também fundamentais, pois ligados à segurança do processo. (BEDAQUE, 2007, p. 49), (grifos nossos).

No entanto, outra parte da doutrina se baliza na célebre assertiva de Chiovenda:

"O processo deve dar, quanto for possível praticamente, a quem tem um direito, tudo aquilo e exatamente aquilo que ele tenha direito de conseguir." (CHIOVENDA, 2000, v. 1, p. 67). Do original: 'Il processo deve dare per quanto è possibile praticamente a chi ha um diritto tutto quello $e$ proprio quello ch'égli há diritto conseguire.

O consagrado jurista Barbosa Moreira baliza-se na famosa premissa de Chiovenda e define Efetividade como:

a) o processo deve dispor de instrumentos de tutela adequados, na medida do possivel, a todos os direitos (e outras posições jurídicas de vantagem) contemplados no ordenamento, quer resultem de expressa previsão normativa, quer se possam inferir do sistema;

b) esses instrumentos devem ser praticamente utilizáveis, ao menos em princípio, sejam quis forem os supostos titulares dos direitos (e das outras posições jurídicas de vantagem) de cuja preservação ou reintegração se cogita, inclusive quando 
indeterminado ou indeterminável o círculo dos eventuais sujeitos;

c) impede assegurar condições propícias à exata e completa reconstituição dos fatos relevantes, a fim de que o convencimento do julgador corresponda, tanto quanto puder à realidade;

d) em toda a extensão da possibilidade prática, o resultado do processo há de ser tal que assegure à parte vitoriosa o gozo pleno da específica utilidade a que faz jus segundo o ordenamento;

e) cumpre que se possa atingir semelhante resultado com o mínimo dispêndio de tempo e energias. (MOREIRA, 1995, p. 97), (grifos nossos).

Assim, para Barbosa Moreira o conceito de Efetividade é sinônimo de eficiente, cuja aptidão para desempenhar do melhor modo possível a função própria do processo, com o escopo de atingir da maneira mais perfeita o seu fim específico.

A posição defendida por Barbosa Moreira é agasalhada por Cesar Asfor Rocha:

A jurisdição, para ser efetiva, necessita que a tutela por ela prestada seja eficaz, isto é, que o vencedor da demanda obtenha o bem da vida pleiteado no processo em um período de tempo razoável. (ROCHA, 2007, p. cit. 39).

Em sua brilhante análise o Ministro Sálvio de Figueiredo Teixeira encontrase a síntese das teses defendidas por Dinamarco e Barbosa Moreira.

Como se vê desta síntese das lições de alguns dos nossos mais autorizados especialistas, cujas reflexões convergem na essência, e em cujas linhas igualmente perfilam os mais atualizados processualistas contemporâneos, nacionais e estrangeiros, se a efetividade não constitui propriamente um princípio informador da ciência processual, mesmo tomado esse como idéia diretora, a encerrar conteúdo de política processual, sem embargo de não constituir princípio autônomo, repita-se, orienta o intérprete e o aplicador da lei quanto à sua melhor inteligência e o seu verdadeiro alcance, inspira o legislador na adoção de novos institutos ou mesmo no aprimoramento e na atualização do sistema legal. Em outras palavras, a efetividade é idéia ínsita ao instituto do processo e à própria ciência processual. (TEIXEIRA, 1993, p. 06), (grifos nossos).

Não obstante, há outros doutrinadores, como Humberto Theodoro Júnior, que dão ênfase a segurança jurídica como meio de assegurar a Efetividade.

(...) Efetivo, portanto, é o processo justo, ou seja, aquele que, com a celeridade possível, mas com respeito à segurança jurídica (contraditório e ampla defesa), proporciona 
às partes o resultado desejado pelo direito material' (THEODORO, v. 1, 2008, p. 20).

Enquanto outros ressaltam a sua natureza constitucional.

Numa visão mais ampla, a efetividade do processo constitui a expressão resumida da idéia de que o processo deve ser apto a cumprir integralmente toda a sua função sociopolíticajurídica, atingindo em toda sua plenitude todos os escopos institucionais. Uma vez que o estado assumiu o monopólio da jurisdição, vedando a autotutela, uma prestação jurisdicional ineficaz representa violação ao princípio da proteção judiciária, o que induz à conclusão de que a efetividade do processo constitui um direito fundamental do cidadão brasileiro, garantia indissociável do Estado Democrático de Direito. (ARRUDA, 2005, p. 66).

Portanto, concluímos que Efetividade é um direito constitucional fundamental, cujo escopo é o desempenho concreto de sua função social, ou seja, que a parte vencedora da lide receba o que lhe é devido, com razoável duração do tempo do processo e a observância da segurança jurídica.

Assim, o Estado que detém o monopólio da violência e veda a autotutela assegura a prestação jurisdicional aos cidadãos através de um processo Efetivo.

\section{A efetividade é princípio processual?}

É mister investigar, ainda, se a Efetividade é um principio do direito processual para os fins do presente trabalho.

Parte da doutrina ensina que a Efetividade tem dupla natureza juridica, ou seja, é um princípio constitucional e processual, se não vejamos:

$\mathrm{O}$ princípio da efetividade do processo ou da jurisdição também repousa na locução contida no art. $5^{\circ}, \mathrm{XXXV}$, de que a lei não excluirá nenhuma lesão ou ameaça a direito da apreciação do 'princípio do acesso à justiça'. Este princípio, por vezes, é enunciado como 'efetividade da jurisdição. (BUENO, v 2008, p. 148).

Já o princípio da máxima efetividade desvela que, quando da interpretação de uma norma constitucional, o intérprete deve procurar o sentido que mais eficácia dê à norma constitucional. (ROCHA, 2007, p. 66).

Sem discutir, nesta sede, a existência ou não de hierarquia entre princípios, pode-se afirmar que a efetividade do processo é um deles, e vem merecendo especial atenção dos constitucionalistas e dos processualistas. (LOPES e LOPES, 2008, p. 241). 
O princípio da segurança jurídica encontra seu fundamento constitucional no art. $5^{\circ}$, LIV, que versa sobre o devido processo legal. Ademais, é conseqüência lógica do Estado Democrático de Direito adotado pela Constituição Federal de 1988 (art. $1^{\circ}, c a p u t$ ). Já a efetividade é princípio constitucional decorrente da norma disposta no art. $5^{\circ}$,

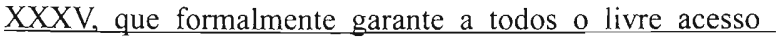
ao Poder Judiciário mas que atualmente é interpretada de forma mais ampla, atribuindo-se um conteúdo substancial, no sentido de não só garantir o acesso ao judiciário, mas de impor ao Estado a efetiva prestação jurisdicional em prazo razoável, de forma a preservar, verdadeiramente, os direitos e interesses daquele que busca a tutela Estatal. (BUSATO, Sérgio Eduardo. O processo civil contemporâneo. Paper), (grifos nossos).

No entanto, parte da doutrina se refere a Efetividade como princípio de natureza processual, como se depreende dos textos a seguir citados.

Efetividade, celeridade e economia processual são importantíssimos princípios processuais relacionados diretamente com a promessa constitucional de acesso à Justiça. (BEDAQUE, 2007, p. 50).

Da cláusula geral do 'devido processo legal' podem ser extraídos todos os princípios que regem o direito processual. É dela, por exemplo, que se extrai o princípio da efetividade: os direitos devem ser, além de reconhecidos, efetivados. Processo devido é processo efetivo. O princípio da efetividade garante o direito fundamental à tutela executiva, que consiste "na exigência de um sistema completo de tutela executiva, no qual existam meios executivos capazes de proporcionar pronta e integral satisfação a qualquer direito merecedor de tutela executiva. (DIDIER, 2009, p. 47).

Por outro lado, como já foi anotado anteriormente, Ney Arruda Filho entende que a Efetividade é "direito fundamental do cidadão brasileiro, garantia indissociável do Estado Democrático de Direito", ou seja, não necessariamente é um princípio constitucional e/ou processual.

O Ministro Sálvio de Figueiredo Teixeira assevera que embora a Efetividade não constitua um princípio processual é inerente a ciência processual.

Aptidão, método, orientação, postura científica ou mesmo princípio, tendo um pouco de cada um e em nenhum deles se confinando, o certo é que cada vez mais sua presença se faz notar entre os pensadores e mais e mais se reclama sua incidência como fator imprescindível de um bom processo e de uma boa Justiça.

(...) se a efetividade não constitui propriamente um princípio informador da ciência processual, mesmo tomado esse como 
idéia diretora, a encerrar conteúdo de política processual, sem embargo de não constituir princípio autônomo, repitase, orienta o intérprete e o aplicador da lei quanto à sua melhor inteligência e o seu verdadeiro alcance, inspira o legislador na adoção de novos institutos ou mesmo no aprimoramento e na atualização do sistema legal. Em outras palavras, a efetividade é idéia ínsita ao instituto do processo e à própria ciência processual. (TEIXEIRA, 1993, p. 02 e 06), (grifos nossos).

Também se observa que o princípio da Efetividade é recepcionado pela nova geração dos processualistas do Direito do Trabalho, se não vejamos:

Finalizamos esse tópico procurando demonstrar que o manejo do princípio da efetividade no processo do trabalho pode ser aplicado sem violar as disposições expressas na CLT ou no próprio CPC. (VEZZONI, 2008, p. 102).

Por fim, merece destaque que parte considerável da doutrina processual não enfrenta a discussão sobre a natureza jurídica da Efetividade.

Em face da pesquisa realizada entendemos que Efetividade é princípio constitucional e processual, que adquire maior relevância neste momento histórico, posto que encontra-se positivada no ordenamento jurídico pátrio, através do art. $5^{\circ}$, inciso XXXV, da Constitucional Federal.

Ressalta-se que os princípios gerais do direito decorrem do próprio fundamento da legislação positiva, ainda que estes não sejam necessariamente expressos, e consistem na manifestação do próprio espírito da legislação.

Também é de se notar que os princípios do direito tem conteúdo ideológico e dependem da vontade do legislador em dar conotação política a positivação das normas, se não vejamos:

Os princípios gerais de direito positivo se revestem de nítido conteúdo ideológico, pois refletem a orientação de cada concepção política no tempo e no espaço. (ACQUAVIVA, p. 664).

\section{A efetividade nas reformas do CPC}

A discussão da Efetividade adquire relevância cada vez maior em face da reestruturação do capitalismo, que exige que o Estado racionalize seus órgãos para acompanhar o desenvolvimento da produção e das transações financeiras através da informatização da sociedade e da economia.

Observa-se, novamente, que após a Constituição Federal de 1988 foram assegurados diversos direitos que aumentaram a demanda judicial. 
É fato que o Poder Judiciário não acompanhou a demanda processual e perdeu o rumo da história quanto à informatização e administração judicial, sem citar os seus próprios desmandos, ocultos durante a ditadura militar até a criação do Conselho Nacional da Justiça, se não vejamos.

Incentivos do CNJ, como fornecimento do Projudi e doação de equipamentos, ajudam os tribunais a saírem da estaca zero tecnológica, mas para especialistas em gestão da informação, essas soluções são bastante limitadas, principalmente para tribunais de grandes estruturas como o Tribunal de Justiça de São Paulo. (Informatização do processo caminha a passos largos - Consultor Jurídico. 07.02.2010).

A má gestão de recursos nos tribunais é a principal causa da morosidade da Justiça no Brasil. É o que apontou a pesquisa Justiça em Números - Novos Ângulos, feita pela professora Maria Tereza Sadek a pedido da Associação dos Magistrados do Brasil (AMB). 'Carga de trabalho, falta de computadores, número de juizes, orçamento. Nada disso é um problema para o Judiciário. $\mathrm{O}$ grande problema está na gestão de recursos' afirmou ela. (Má administração de tribunais prejudica Judiciário - Consultor Jurídico. 29.10.2009).

A situação tornou-se insustentável nos tribunais e o Estado foi obrigado a intervir por meio de reformas legislativas em todos os setores do direito, é o que se depreende do chamado "I e II Pacto Republicano"

O I Pacto Republicano, assinado em 2004, logo após a Reforma do Judiciário (Emenda Constitucional 45/2004), teve como principal objetivo a aprovação de leis que permitissem o uso de novos instrumentos e a criação de mecanismos que abrissem as portas do Judiciário para quem ainda não tem acesso, para agilizar o andamento dos processos e, com isso, dar maior efetividade e racionalidade à Justiça brasileira.

O II Pacto, fechado em abril de 2009, atua firme na criação de políticas públicas que aplique as disposições das normas aprovadas, com foco na agilidade e efetividade da Justiça e da concretização dos direitos humanos e fundamentais (...) (Pacto Republicano avança com políticas públicas Consultor Jurídico. 12.09.2009).

Assim verificamos a alteração da norma constitucional através da Emenda Constitucional n. 45 , que deu a seguinte redação ao art. $5^{\circ}$, inciso LXXVIII, da Constituição Federal, in verbis:

A todos, no âmbito judicial e administrativo, são assegurados a razoável duração do processo e os meios que garantam a celeridade de sua tramitacão. (grifos nossos). 
Neste sentido a vontade do legislador encontra ressonância nos reclamos da doutrina processualista.

As reformas do CPC realizadas até aqui são um grande avanço para uma maior efetividade da jurisdição mas não 'a' solução de todos os problemas da inefetividade jurisidiconal. Por quê? Porque as reformas - sobretudo as que ocorreram entre 1994 e 2001 - atuaram muito mais no chamado "processo de conhecimento" aprimorando-o, é certo, mas deixando para um segundo momento o "processo de execução' Com as reformas já realizadas e com as que já estão desenhadas cabe - sempre com os olhos voltados ao 'modelo constitucional do processo' - extrair o máximo da ruptura (...)

Somente com a Lei n. 10.444/02 é que a verdadeira efetividade jurisdicional foi claramente colocada no sistema porque é nesta lei - e não antes - que se revolucionou, em definitivo, o sistema amalgamando, vez por todas, o 'conhecer' e o 'executar' de determinadas situações conflituosas de direito material (...). (BUENO, 2006, p. 368 e 369).

É por esta razão que as recentes reformas do Código de Processo Civil, por meio de Leis Ordinárias, também conhecidas como "mini-reformas", foram impulsionadas com o escopo de dar maior celeridade e efetividade ao Processo Civil, em face das demandas sociais e econômicas e do congestionamento do Judiciário.

Porém as reformas introduzidas no CPC trouxeram instabilidade ao sistema, razão pela qual foi criada comissão de juristas para elaboração do novo Código de Processo Civil.

A comissão de juristas encarregada da elaboração do anteprojeto do novo Código de Processo Civil (CPC) tem 180 dias para finalizar seu texto e encaminhar a sugestão ao Congresso. Na primeira reunião, o grupo de juristas presidido pelo ministro do Superior Tribunal de Justiça (STJ), Luiz Fux, destacou a importância de acelerar os processos, incentivar a modernização da Justiça e garantir a construção de um texto simples e claro.

Durante o encontro, forma aprovadas ações que favorecem a celeridade da Justiça, como a adequação do Código de Processo Civil com a lei do processo eletrônico para compatibilizar a comunicação dos atos processuais com as modernas tecnologias de comunicação e informação." (Agilidade será princípio do CPC - Jornal do Commercio. 10.12.2009).

O Ministro Luiz Fux, Presidente da Comissão de Juristas, assevera no Anteprojeto enviado ao Senado que "sem violação de qualquer comando constitucional, visou tornar efetivamente alcançável a duração razoável dos processos, promessa 
constitucional e ideário de todas as declarações fundamentais dos direitos do homem e de todas as épocas e continentes, mercê propiciar maior qualificação da resposta judicial, realizando o que Hans Kelsen expressou ser o mais formoso sonho da humanidade, o sonho de justiça"

Em entrevista ao jornal Valor Econômico o Ministro Luiz Fux confirma a orientação do novo CPC, "a idéia central do novo código é reduzir o tempo de tramitação dos processos judiciais - que chega a 20 anos - para dois anos. 'Estamos em um momento em que o valor celeridade é mais importante do que o valor segurança"' (Mudanças em código vão desafogar o STJ - Valor Econômico. 23.12.2009).

Assim, depreende-se que as reformas introduzidas no CPC, com o escopo de dar maior efetividade ao processo, resolveram o problema de forma paliativa, trazendo inclusive instabilidade ao sistema, razão pela qual faz-se necessário a redação de um novo Código de Processo Civil que dê Efetividade as decisões judiciais e celeridade processual, sem prejuízo do contraditório e da ampla defesa, ou seja, da segurança jurídica.

\section{Conclusões}

Verificamos através desta pesquisa que a Efetividade é princípio constitucional e processual, posto que é direito fundamental, assegurado constitucionalmente, cujo escopo é o desempenho concreto de sua função social, ou seja, que a parte vencedora da lide receba o que the é devido, com razoabilidade duração do tempo do processo e a observância da segurança jurídica e da celeridade, sendo que o Estado assegura a prestação jurisdicional através de um processo Efetivo.

Neste sentido, é mister ressaltar que a Efetividade prescinde da técnica processual para alcançar o resultado desejado pelo direito material, e assim, assegurar-se da ampla defesa e do contraditório dentro do processo, visto que somente a celeridade não é suficiente para alcançar o escopo da Efetividade.

Para a melhor doutrina estamos na fase instrumentalista do processo (máxima efetividade da jurisdição), onde se busca um "processo civil de resultado"

Ensina o ilustre Mestre Cândido Rangel Dinamarco que a tutela jurisdicional é o resultado prático do processo.

Assim, entendemos que a doutrina processualista e o Estado estão em consonância com as mudanças socioeconômicas e as demandas dos atores sociais na busca da resolução de conflitos de forma Efetiva.

\footnotetext{
"Yo no canto por cantar

Ni por tener buena voz

Canto por que la guitarra

Tiene sentido y razón

(...)

Mi canto és de los andarios
} 


\section{Para alcanzar las estrellas \\ Que el canto tiene sentido \\ Quando palpita en las venas" \\ (Victor Jara - Manifiesto)}

São Paulo, dezembro de 2010.

\section{Referências}

AMENDOEIRA JUNIOR, Sidnei. Os princípios processuais e o devido processo constitucional. Aula 05, 25.03.2008, paper GV/Law.

ARRUDA FILHO, Ney. A efetividade do processo, como direito fundamental. Porto Alegre: Norton Editor, 2005.

BARROSO, Luís Roberto. Interpretação e aplicação da Constituição. São Paulo: Saraiva, 1996.

BEDAQUE, José Roberto dos Santos. Efetividade do processo e técnica processual. 2. ed. São Paulo: Malheiros Editores Ltda., 2007.

BUENO, Cassio Scarpinella. A nova etapa da reforma do Código de Processo Civil: comentários sistemáticos às Leis n. 11.187, de 19.10.2005, e 11.232, de 22.12.2005. 2. ed. rev., atual. e ampl. São Paulo: Saraiva, 2006. v. 1.

BUENO, Cássio Scarpinella. Curso sistematizado de direito processual civil: teoria geral do direito processual civil 1.2. ed. rev., atual. e ampl. São Paulo: Saraiva, 2008.

CARMONA, Carlos Alberto et al. Reflexões sobre a reforma do código de processo civil: estudos em homenagem a Ada Pellegrini Grinover, Cândido R. Dinamarco e Kazuo Watanabe. São Paulo: Atlas, 2007.

CHIOVENDA, Giuseppe. Instituições de direito processual civil. Tradução de Paolo Capitanio. 2. ed. Campinas: Bookseller, 2000. v. 1.

CINTRA, Antônio Carlos de Araújo. GRINOVER, Ada Pellegrini. DINAMARCO, Cândido Rangel. Teoria geral do processo. São Paulo: Malheiros Editores, 2008.

CUNHA, Antônio Geraldo da. Dicionário etimológico Nova Fronteira da língua portuguesa. Rio de Janeiro: Nova Fronteira, 1982.

DIDIER JUNIOR, Fredie. Curso de direito processual civil. Execução. Bahia: Editora Juspodium, 2009. v. 5.

DINAMARCO, Cândido Rangel. A instrumentalidade do processo. 13. ed. São Paulo: Malheiros, 2008.

ENGELS, Friedrich. Do Socialismo utópico ao socialismo cientifico. 5. ed. São Paulo: Global Editora e Distribuidora Ltda., 1983. 
FARIA, José Eduardo. Sociologia jurídica: direito e conjuntura. São Paulo: Saraiva, 2008.

FERREIRA, Aurélio Buarque de Holanda. Novo dicionário Aurélio da lingua portuguesa. 3. ed. Curitiba: Positivo, 2004.

GOES, Ricardo Tinoco de. Efetividade do processo e cognição adequada. São Paulo: MP Ed., 2008.

LIEBMAN, Enrico Tullio. Processo de execução. São Paulo: Saraiva, 1986.

LOPES, Maria Elisabeth de Castro et al. Principios processuais civis na constituição. Rio de Janeiro: Elsevier, 2008.

LOPES, Maria Elizabeth de Castro; LOPES, João Batista. Reformas setoriais, harmonia do sistema normativo e efetividade do processo. Revista de Processo, São Paulo, a. 33, n. 162, agosto 2008.

MAGNOLI, Demétrio. A nova geografia: estudos de geografia do Brasil. 1. ed. São Paulo, Moderna, 1992.

MARX, Karl e ENGELS, Friedrich. A ideologia alemã. 3. ed. São Paulo: Livraria Editora Ciências Humanas, 1982.

MOREIRA, José Carlos Barbosa. Efetividade do processo e técnica processual. Revista Forense, Rio de Janeiro, v. 329, 1995.

NEVES, Daniel Amorim Assumpção et al. Reforma do CPC 2: nova sistemática processual civil. São Paulo: Editora Revista dos Tribunais, 2007.

ROCHA, Cesar Asfor. A luta pela efetividade da jurisdição. São Paulo: Editora Revista dos Tribunais, 2007.

SILVA, Ovídio Araújo Baptista da. Processo e ideologia: o paradigma racionalista. Rio de Janeiro: Forense, 2006.

SOUZA JUNIOR, Adugar, Quirino do Nascimento. Efetividade das decisões judiciais e meios de coerção. São Paulo: Editora Juarez de Oliveira, 2003.

TEIXEIRA, Sálvio de Figueiredo. A efetividade do processo e a reforma processual. In: CONGRESSO NACIONAL DE DIREITO PROCESSUAL CIVIL, II., 1993, Porto Alegre. Comemoração aos 20 anos do Código de Processo Civil. Porto Alegre, 1993.

THEODORO JUNIOR, Humberto. Curso de direito processual civil: teoria geral do direito processual civil e processo de conhecimento. Rio de Janeiro: Forense, 2008. v. 1.

WAMBIER, Luiz Rodrigues; WAMBIER, Teresa Arruda Alvim; MEDINA, José Miguel Garcia. Breves comentários à nova sistemática processual civil, 3. São Paulo: Editora Revista dos Tribunais, 2007.

VEZZONI, Marina. Princípios do processo de execução: a correlação entre o sistema processual civil e o trabalhista. Rio de Janeiro: Elsevier, 2008. 